\title{
Industry use of 'better-for-you' features on labels of sugar-containing beverages
}

\author{
Aimee L Brownbill ${ }^{1,2, *}$, Caroline L Miller ${ }^{1,2}$ and Annette J Braunack-Mayer ${ }^{1,3}$ \\ ${ }^{1}$ The University of Adelaide, School of Public Health, Adelaide Health and Medical Sciences Building, Adelaide, SA \\ 5005, Australia: ${ }^{2}$ South Australian Health and Medical Research Institute, Population Health Research, Adelaide, \\ SA, Australia: ${ }^{3}$ University of Wollongong, School of Health and Society, Wollongong, NSW, Australia
}

Submitted 22 March 2018: Final revision received 27 July 2018: Accepted 14 August 2018: First published online 10 October 2018

\begin{abstract}
Objective: To examine the ways in which sugar-containing beverages are being portrayed as 'better-for-you' (BFY) via features on product labels.

Design: Cross-sectional audit of beverage labels.

Setting: Adelaide, Australia. Data on beverage labels were collected from seventeen grocery stores during September to November 2016.

Subjects: The content of 945 sugar-containing beverages labels were analysed for explicit and implicit features positioning them as healthy or BFY.

Results: The mean sugar content of beverages was high at $8.3 \mathrm{~g} / 100 \mathrm{ml}$ and most sugar-containing beverages $(87.7 \%)$ displayed features that position them as BFY. This was most commonly achieved by indicating the beverages are natural $(76.8 \%)$, or contain reduced or natural energy/sugar content $(48.4 \%)$, or through suggesting that they contribute to meeting bodily needs for nutrition (28.9\%) or health $(15 \cdot 1 \%)$. Features positioning beverages as BFY were more common among certain categories of beverages, namely coconut waters, iced teas, sports drinks and juices.

Conclusions: A large proportion of sugar-containing beverages use features on labels that position them as healthy or BFY despite containing high amounts of sugar.
\end{abstract}

Keywords
Sugar-sweetened beverages
Marketing
Advertising
Food labels
Health halo

The high global consumption of sugar-containing beverages has gained international public health attention due to its contribution to obesity ${ }^{(1)}$ and noncommunicable diseases such as type 2 diabetes $^{(2)}$, CVD risk factors ${ }^{(3)}$ and tooth decay ${ }^{(4)}$. A number of governments have introduced policies to reduce consumption of sugar-containing beverages through taxation, restrictions on marketing and public awareness campaigns ${ }^{(5)}$. It is therefore unsurprising that consumers are becoming concerned about the adverse health effects of these beverages $^{(6)}$.

Community concern about sugar consumption appears to have led to changes in the marketing of sugarcontaining beverages, for example through increased advertising of beverages as 'better-for-you' $(\mathrm{BFY})^{(6)}$. 'Better-for-you' is a term used increasingly by the food and beverage industry in marketing publications and in market reports ${ }^{(6,7)}$. It is starting to appear in public-facing websites (e.g. PepsiCo) ${ }^{(8)}$ where 'better-for-you' brands (e.g. Pure Leaf iced teas and Grain Waves) are presented in contrast to 'fun-for-you' brands (e.g. Pepsi and Doritos). The BFY category is broad and ill-defined ${ }^{(6,7)}$, including both health and nutrition claims and products classified as 'good' ('products that generally are considered wholesome') ${ }^{(9)}$.

In Australia, foods and beverages are required to display a Nutrition Information Panel. Nutrition information labels are common in many countries; however, their relative complexity often results in low usage among subpopulations at the highest risk of developing nutritionrelated chronic illnesses ${ }^{(10)}$. Health and nutrition claims are another source of nutritional information provided on food and beverage packages. While it is the manufacturers' decision whether to display health and nutrition claims or not, regulations exist around their use in Australia $^{(11)}$. The use of health and nutrition claims on food and beverage labels is well documented. A number of studies show that consumers believe a product is healthier if it carries a health- or nutrition-related claim ${ }^{(12-15)}$ and a recent meta-analysis concluded that health and nutrition claims have a substantial effect on dietary choices ${ }^{(16)}$. However, these studies often do not address broader, unregulated, BFY features on food and beverage labels, 
which has been identified as a limitation of previous research $^{(17-19)}$.

The present study describes the features on sugarcontaining beverage labels that position them as BFY, encompassing features that include, but are not limited to, health and nutrition claims. We defined a BFY feature as 'text or an image on packaging that either claims or implies that a product has health-related benefits or is a healthier option'. This definition includes both claims that directly state a health benefit and broad terms that imply the product may play a role in health or well-being. The display of BFY features on labels may lead consumers to believe these sugar-containing beverages are healthier for them than they would if the labels did not display BFY features; this is known as a 'health halo' effect ${ }^{(20,21)}$. Understanding the messaging communicated to consumers through the BFY construct has the potential to provide further insight into trends of sugar-containing beverage consumption, including shifts from soda to other beverage types.

\section{Methods}

\section{Data collection}

During September to November 2016 we conducted an audit of labels on all non-alcoholic/non-dairy packaged beverages in South Australian grocery stores. We selected seventeen stores from leading grocery store chains ${ }^{(22)}$. Stores were purposively sampled from across areas of differing socio-economic status according to the 2011 Socio-Economic Index for Areas score ${ }^{(23)}$ to ensure that any potential differences in the availability of beverages in differing socio-economic areas were captured. The method of data collection was based on similar studies of packaged food and beverage label audits ${ }^{(24-26)}$. We photographed the packaging of all non-alcoholic/non-dairy beverages of size 1 litre ( $34 \mathrm{fl}$. oz) or less from each store. Multipacks and packages where information was not presented in English were excluded. The study was granted an exemption from Human Research Ethics Committee review.

\section{Study sample}

We recorded product descriptions (product name, flavour and package size). Product duplicates were removed from the sample. Multiple package sizes were also excluded after initial analysis of a subset of products found no difference between features on different sizes of products.

We classified products by beverage type (alcohol substitutes, coconut water (flavoured or plain), concentrates, energy drinks, fruit drinks, iced teas, juices (100\% juices separated), soda, sports drinks, flavoured water (still or sparkling) and other (i.e. probiotic drinks); see online supplementary material, Supplemental Table 1 for definitions) and recorded the sugar content. For the purposes of the present study, beverages were categorised as either sugar-free $(<1 \mathrm{~g} / 100 \mathrm{ml})$ or sugar-containing $(\geq 1 \mathrm{~g} /$ $100 \mathrm{ml})$. Sugar-containing beverages were further categorised depending on their sugar content as low sugar $(\geq 1$ and $\leq 2.5 \mathrm{~g} / 100 \mathrm{ml})$, medium sugar $(>2.5$ and $<5 \mathrm{~g} / 100 \mathrm{ml}$ ), high sugar $(\geq 5$ and $<10 \mathrm{~g} / 100 \mathrm{ml}$ ) and very high sugar $(\geq 10 \mathrm{~g} / 100 \mathrm{ml})$. Low sugar was categorised based on requirements for making a low sugar claim on packages ${ }^{(11)}$. High and very high sugar were categorised based on WHO recommendations ${ }^{(27)}$, with very high sugar aligning with the recommendation of limiting daily free sugar intake to approximately $50 \mathrm{~g}$, and high sugar aligning with the extended recommendation to limit daily free sugar intake to $25 \mathrm{~g}$ (calculations based on a standard 500-600 ml ready-todrink beverage). Free sugar is defined as 'monosaccharides and disaccharides added to foods and beverages by the manufacturer, cook or consumer, and sugars naturally present in honey, syrups, fruit juices and fruit juice concentrates $^{,(27)}$. For the purposes of the current study, this means simple sugars added to beverages and those naturally present within juice. Products in the final sample were assigned unique identifiers for products and their accompanying images.

\section{Data analysis}

Beverage labels were analysed through content analysis ${ }^{(28)}$. Using the definition of BFY features above, we developed a coding framework for the content analysis (see online supplementary material, Supplemental Table 2). The coding framework was based firstly on health and nutrient content claims, as defined by the Food Standards Australia New Zealand Code on Nutrition Health and Related Claims ${ }^{(29)}$, and secondly on relevant literature on food packaging which has suggested that particular features on packages are perceived to imply health benefits. We conducted an initial analysis to refine categories and capture new codes. Through this process, we identified four new codes (superfoods, goodness, wellness and isotonic/hypotonic). The coding framework was further developed and refined through an iterative process that included coding random sub-samples and discussing any issues among the authors until consensus was reached. Before finalising the framework, an independent researcher was engaged to code a random subsample $(2.5 \%)$ of products and any disagreements or problems with the framework were discussed among the authors until consensus was reached. The final coding framework consisted of thirty-one codes for BFY features which were grouped into eight categories (presented below). Beverage labels were coded by the lead author for the presence or absence of each BFY feature anywhere on the label. At completion, a random sub-sample (10\%) of products was coded by an independent researcher and the percentage agreement was calculated (mean percentage 
agreement: $94.5 \%$; range: $77-100 \%)$. Cohen's $\kappa$ and other similar inter-rater reliability tests were not used because the underlying assumptions do not fit our data set. The $\kappa$ statistic corrects for the percentage agreement due to chance agreement, which is assumed to apply to all observed ratings. However, this assumption is problematic when there is a low likelihood of chance agreement, such as when the prevalence of one outcome is high (e.g. large proportion of zeros due to the absence of a characteristic) as was the case in our data set. The nature of our data set aligns well with circumstances in which percentage agreement is an appropriate measure ${ }^{(30)}$.

\section{Results}

We identified 1123 unique beverage products, of which $84 \%$ ( $n$ 945) contained sugar. The sugar-containing beverages formed the sample for the subsequent analysis. Only $5 \cdot 2 \%$ ( $n$ 49) of the sugar-containing beverages were low in sugar. The mean sugar content of beverages was $8 \cdot 3$ (sD 3.2) g/100 $\mathrm{ml}$ and ranged from 1.0 to $16 \cdot 9 \mathrm{~g} / 100 \mathrm{ml}$ (excluding beverages with missing ( $n$ 4) or nonstandardised ( $n$ 10) reporting of sugar content on labels). Energy drinks had the highest mean sugar content followed by soda and $100 \%$ juices, with a large proportion of beverages within these categories containing a high or very high sugar content (100.0, 96.2 and 98.0\%, respectively). Although coconut waters and iced teas on average had lower amounts of sugar than other beverage categories, over a third of beverages within these categories were high in sugar (see Table 1).

Almost all sugar-containing beverages contained BFY features on their labels $(96.8 \%)$, with $90.5 \%$ of packages displaying fruit or vegetable features. When fruit or vegetable features were excluded, BFY features remained on a large proportion of products $(87.7 \%)$, with a mean of 3.3 (sD 2.6) unique BFY features per product. Most beverages carried at least one BFY feature (see Table 2). Coconut waters carried the highest number of unique BFY features with an average of eight BFY features per product. Although beverages within the soda and energy drink categories had fewer BFY features on packages, at least one BFY feature was still present on over two-thirds of sodas $(68.4 \%)$ and roughly two-thirds of energy drinks $(62 \cdot 1 \%)$.

\section{Better-for-you features}

Fruit or vegetables

The majority ( $86.3 \%)$ of beverages had text referring to fruit or vegetables on their packages and $61.1 \%$ had an image of fruit or vegetables (Table 3). Energy drinks were the only type of beverage on which it was rare for images of fruit or vegetables to be displayed $(3.4 \%$; see online supplementary material, Supplemental Table 3). Fruit drinks and sparkling flavoured waters commonly displayed the servings or percentage of fruit or vegetables on their labels $(52.7$ and $40 \cdot 0 \%$, respectively). Just under a third of beverage labels (29.1\%) mentioned 'superfoods', with the most common superfoods being coconut ( $8.7 \%)$,

Table 1 Sugar content of sugary beverages by beverage category: South Australian supermarkets ( $n$ 17), September-November 2016

\begin{tabular}{|c|c|c|c|c|c|c|c|}
\hline \multirow[b]{2}{*}{ Beverage type } & \multirow[b]{2}{*}{$\begin{array}{l}\text { No. of beverages } \\
(n 931)^{\star}, \dagger\end{array}$} & \multicolumn{6}{|c|}{ Sugar content $(\mathrm{g} / 100 \mathrm{ml})$} \\
\hline & & Mean & SD & $\begin{array}{l}\text { Low sugar }(\geq 1 \text { and } \\
\leq 2.5)(\%) \ddagger\end{array}$ & $\begin{array}{l}\text { Medium sugar }(>2.5 \\
\text { and }<5)(\%) \ddagger\end{array}$ & $\begin{array}{l}\text { High sugar }(\geq 5 \text { and } \\
<10)(\%) \ddagger\end{array}$ & $\begin{array}{l}\text { Very high sugar } \\
\quad(\geq 10)(\%) \ddagger\end{array}$ \\
\hline Energy drink & 29 & 12 & 1.7 & 0.0 & 0.0 & $6 \cdot 9$ & 93.1 \\
\hline Soda & 132 & 11 & 2.0 & 0.8 & 3.0 & $16 \cdot 7$ & 79.5 \\
\hline Juice, $100 \%$ & 293 & 10 & $2 \cdot 2$ & 0.0 & $2 \cdot 0$ & $51 \cdot 9$ & $46 \cdot 1$ \\
\hline $\begin{array}{l}\text { Alcohol } \\
\text { substitute }\end{array}$ & 25 & 9 & 3.5 & 0.0 & $16 \cdot 0$ & $36 \cdot 0$ & $48 \cdot 0$ \\
\hline $\begin{array}{l}\text { Water, flavoured } \\
\text { mineral }\end{array}$ & 50 & 9 & $2 \cdot 3$ & 0.0 & $10 \cdot 0$ & $54 \cdot 0$ & $36 \cdot 0$ \\
\hline Fruit drink & 91 & 8 & 3.6 & $8 \cdot 8$ & $17 \cdot 6$ & 33.0 & $40 \cdot 6$ \\
\hline $\begin{array}{l}\text { Juice (not } \\
\qquad 100 \%)\end{array}$ & 33 & 8 & $3 \cdot 1$ & $6 \cdot 1$ & $9 \cdot 1$ & $63 \cdot 6$ & $21 \cdot 2$ \\
\hline Concentrate & 83 & 7 & 2.5 & $2 \cdot 4$ & $13 \cdot 2$ & 68.7 & $15 \cdot 7$ \\
\hline Sports drink & 39 & 5 & 1.3 & $2 \cdot 6$ & $15 \cdot 4$ & $82 \cdot 0$ & 0.0 \\
\hline $\begin{array}{l}\text { Coconut water, } \\
\text { flavoured }\end{array}$ & 25 & 5 & $1 \cdot 3$ & 0.0 & $52 \cdot 0$ & $48 \cdot 0$ & 0.0 \\
\hline Iced tea & 78 & 4 & $2 \cdot 2$ & $24 \cdot 3$ & 38.5 & $37 \cdot 2$ & 0.0 \\
\hline $\begin{array}{l}\text { Coconut water, } \\
\text { plain }\end{array}$ & 35 & 4 & $1 \cdot 1$ & 8.6 & $57 \cdot 1$ & $34 . \overline{3}$ & 0.0 \\
\hline $\begin{array}{l}\text { Water, flavoured } \\
\text { still }\end{array}$ & 13 & 3 & $1 \cdot 2$ & $53 \cdot 8$ & $46 \cdot 2$ & 0.0 & 0.0 \\
\hline $\begin{array}{l}\text { Other (probiotic } \\
\text { drinks) }\end{array}$ & 5 & 2 & 0.0 & $100 \cdot 0$ & 0.0 & 0.0 & 0.0 \\
\hline
\end{tabular}

${ }^{*}$ Beverages missing sugar content on labels $(n 4)$.

†Beverages removed due to unstandardised reporting of sugar content, i.e. concentrates not as mixed with water ( $n$ 10).

$\ddagger$ Reported as percentage of beverage category. 
Table 2 Better-for-you (BFY) features on sugary beverage labels by beverage category*, $\dagger$ : South Australian supermarkets ( $n$ 17), September-November 2016

\begin{tabular}{|c|c|c|c|c|c|c|}
\hline Beverage type & $\begin{array}{c}\text { No. of beverages } \\
(n 945)\end{array}$ & $\begin{array}{l}\text { Mean no. of BFY } \\
\text { features }\end{array}$ & $\mathrm{SD}$ & $\begin{array}{l}\text { Minimum no. of BFY } \\
\text { features }\end{array}$ & $\begin{array}{l}\text { Maximum no. of BFY } \\
\text { features }\end{array}$ & $\begin{array}{c}\text { Presence of at least one BFY } \\
\text { feature }(\%) \ddagger\end{array}$ \\
\hline $\begin{array}{l}\text { Coconut water, } \\
\text { flavoured }\end{array}$ & 25 & 8.0 & $2 \cdot 8$ & 3 & 13 & $100 \cdot 0$ \\
\hline $\begin{array}{l}\text { Coconut water, } \\
\text { plain }\end{array}$ & 35 & 7.9 & 3.0 & 1 & 13 & $100 \cdot 0$ \\
\hline Iced tea & 78 & 5.5 & $2 \cdot 3$ & 1 & 10 & $100 \cdot 0$ \\
\hline Sports drink & 41 & $5 \cdot 1$ & $2 \cdot 1$ & 3 & 10 & $100 \cdot 0$ \\
\hline Juice (not $100 \%$ ) & 33 & 3.9 & 2.3 & 0 & 8 & $90 \cdot 9$ \\
\hline Juices, $100 \%$ & 293 & 3.8 & 1.8 & 0 & 10 & $97 \cdot 3$ \\
\hline Fruit drink & 91 & $2 \cdot 7$ & 1.8 & 0 & 7 & 92.3 \\
\hline $\begin{array}{l}\text { Water, flavoured } \\
\text { still }\end{array}$ & 13 & $2 \cdot 3$ & 0.6 & 1 & 3 & $100 \cdot 0$ \\
\hline $\begin{array}{l}\text { Water, flavoured } \\
\text { mineral }\end{array}$ & 50 & 1.8 & 1.6 & 0 & 5 & $80 \cdot 0$ \\
\hline Alcohol substitute & 29 & 1.8 & 1.5 & 0 & 4 & $79 \cdot 3$ \\
\hline Concentrate & 90 & 1.5 & 1.4 & 0 & 7 & $67 \cdot 8$ \\
\hline Soda & 133 & 1.2 & 1.2 & 0 & 4 & 68.4 \\
\hline Energy drink & 29 & 1.0 & 1.0 & 0 & 4 & $62 \cdot 1$ \\
\hline $\begin{array}{l}\text { Other (probiotic } \\
\text { drinks) }\end{array}$ & 5 & $6 \cdot 0$ & 0.0 & 6 & 6 & $100 \cdot 0$ \\
\hline
\end{tabular}

*Excluding fruit or vegetable features.

†Reported as the occurrence of any one type of feature.

†Reported as percentage of beverage category.

berries (6.3\%), ginger $(6.2 \%)$ and green tea/kombucha (5.4\%). Superfoods were most frequently included on the labels of coconut waters (100.0\% of labels; expected as coconut waters in themselves are considered a superfood), iced teas (59.0\%), juices (45.5\%) and $100 \%$ juices $(27 \cdot 0 \%)$.

\section{Natural}

Three-quarters of beverages (76.8\%) contained features that implied they were natural products, by using the term 'natural', 'organic', 'fresh', 'real', 'pure' or 'raw' or by stating an absence of artificial products (i.e. additives, preservatives, colours etc.). All iced teas, over $90 \%$ of coconut waters and $100 \%$ juices, and over $80 \%$ of fruit drinks and juices described their products as natural. Of sodas, $61.7 \%$ also included features on labels that described them as natural, with $31.6 \%$ using the term 'natural' itself and $32 \cdot 3 \%$ stating an absence of artificial products.

\section{Energy and sugar content}

Almost half of the sugar-containing beverages (48.4\%) referred to the product containing lowered, or natural, energy or sugar content, with 'no added sugars' and 'no concentrates' the most frequently used terms. Coconut waters and $100 \%$ juices were the most common types of beverages to carry these features with over $80 \%$ of products displaying one or more feature. More specifically, $78.2 \%$ of $100 \%$ juices and $62.9 \%$ of plain coconut waters contained a no added sugar claim and $40 \cdot 3 \%$ of $100 \%$ juices and $60.0 \%$ of coconut waters (both plain and flavoured) contained a no concentrates claim. Coconut waters also had no/low-fat or cholesterol claims (60.0\% plain and $76.0 \%$ flavoured). A small number of beverage packages $(7.9 \%)$ stated that the product was naturally sweetened or that the sugar was natural or from fruit.

\section{Nutrition}

Over a quarter of beverages contained features that focused on nutrition (28.9\%). This was most commonly achieved through referring to specific nutrients (25.6\%) such as 'high in vitamin C'. Although this occurred across beverage types, it was most often used on sports drinks (68.3\%) and coconut waters (60.0\% flavoured and plain). Beverages also used broad terms such as 'nutritious'/ 'nourishing' (5.7\%) and this was most common on juices ( $27 \cdot 3 \%$ of juices and $12 \cdot 3 \%$ of $100 \%$ juices).

\section{Health}

Fifteen per cent of beverages contained features that were specifically related to health and well-being. Broad terms such as 'health'/'healthy' were present most often on iced tea packages $(32 \cdot 1 \%)$ and coconut waters $(28.6 \%$ plain and $16.0 \%$ flavoured), and terms such as 'wellness'/'wellbeing' or 'revitalise'/refresh' were most common on energy drinks (27.6\%), alcohol substitutes (24.1\%) and juices (24.2\%). References to specific health effects (e.g. claims about metabolism, cardiovascular/muscle function, immune system or digestive health) were less common; when present, these were most commonly found on juices (18.2\%) and iced teas (12.8\%).

\section{Goodness}

Fifteen per cent of beverages used the term 'goodness' (e.g. 'full of goodness' or 'the goodness of blueberry'). This was most commonly used on juice labels $(60 \cdot 6 \%$ of juices 
Table 3 Better-for-you (BFY) features on sugary beverage labels: South Australian supermarkets ( $n$ 17), September-November 2016

\begin{tabular}{|c|c|c|}
\hline $\begin{array}{l}\text { BFY feature category/ No } \\
\text { code }\end{array}$ & $\begin{array}{l}\text { Jo. of beverages } \\
(n 945)\end{array}$ & $\begin{array}{c}\text { Proportion of } \\
\text { beverages (\%) }\end{array}$ \\
\hline Fruit or vegetables & 855 & $90 \cdot 5$ \\
\hline Fruit/vegetables in text & 816 & $86 \cdot 3$ \\
\hline Images of fruit/vegetables & 577 & $61 \cdot 1$ \\
\hline Superfoods & 275 & $29 \cdot 1$ \\
\hline $\begin{array}{l}\text { Servings or \% fruit/ } \\
\text { vegetables }\end{array}$ & 173 & $18 \cdot 3$ \\
\hline Natural & 726 & $76 \cdot 8$ \\
\hline No artificial products & 576 & $61 \cdot 0$ \\
\hline Natural & 316 & 33.4 \\
\hline Pure or raw & 152 & $16 \cdot 1$ \\
\hline Fresh & 119 & $12 \cdot 6$ \\
\hline Real & 115 & $12 \cdot 2$ \\
\hline Organic & 111 & 11.7 \\
\hline Energy and sugar content & 457 & $48 \cdot 4$ \\
\hline No added sugar & 300 & 31.7 \\
\hline No concentrates & 176 & $18 \cdot 6$ \\
\hline $\begin{array}{l}\text { Naturally sweetened/ } \\
\text { sugar from fruit }\end{array}$ & 75 & $7 \cdot 9$ \\
\hline Low kilojoules & 51 & $5 \cdot 4$ \\
\hline No/low fat or cholesterol & 42 & 4.4 \\
\hline $\begin{array}{l}\text { Low/reduced sugar } \\
\text { or \% sugar-free }\end{array}$ & 40 & $4 \cdot 2$ \\
\hline Unsweetened & 3 & 0.3 \\
\hline Nutrition & 273 & 28.9 \\
\hline Listed specific nutrients & 242 & $25 \cdot 6$ \\
\hline Nutritious or nutritional & 54 & $5 \cdot 7$ \\
\hline Health & 143 & $15 \cdot 1$ \\
\hline Wellness & 87 & $9 \cdot 2$ \\
\hline Health/healthy & 72 & $7 \cdot 6$ \\
\hline Health effects & 36 & $3 \cdot 8$ \\
\hline Goodness & 139 & 14.7 \\
\hline Dietary restrictions & 123 & $13 \cdot 0$ \\
\hline Gluten free & 98 & $10 \cdot 4$ \\
\hline Vegetarian or vegan & 51 & $5 \cdot 4$ \\
\hline Dairy/lactose free & 26 & $2 \cdot 8$ \\
\hline Sport & 104 & $11 \cdot 0$ \\
\hline Hydration or rehydrate & 79 & 8.4 \\
\hline Electrolytes & 70 & 7.4 \\
\hline Sport or exercise & 59 & $6 \cdot 2$ \\
\hline Isotonic or hypotonic & 24 & 2.5 \\
\hline Performance & 12 & $1 \cdot 3$ \\
\hline
\end{tabular}

and $22 \cdot 2 \%$ of $100 \%$ juices), iced teas (30.8\%) and sparkling flavoured waters $(24 \cdot 0 \%)$.

\section{Dietary restrictions}

A small number of products noted that the beverage was suitable for people with dietary restrictions (13.0\%), with gluten free being the most common (10.4\%). Flavoured coconut waters were the most likely to indicate that they were suitable for a range of dietary restrictions such as gluten free, vegan and lactose free, with $60 \cdot 0 \%$ containing at least one or more $(37 \cdot 1 \%$ in plain coconut waters), followed by iced teas which had $43.6 \%$ of products containing one or more feature per package.

\section{Sport}

Although there were relatively few sporting features on beverage packages across the sample (11.0\%), all sports drinks contained sporting features and specifically referenced sport or exercise, with other commonly used features on sports drinks being electrolytes (100.0\%) and hydration $(78.0 \%)$. In addition, most coconut waters also displayed sporting features on packages $(88.0 \%$ of flavoured and $77.1 \%$ of plain), often through reference to hydration $(68.0 \%$ of flavoured and $68.6 \%$ of plain) and electrolytes $(52.0 \%$ of flavoured and $45.7 \%$ of plain), and less commonly through direct reference to sport or exercise $(24.0 \%$ of flavoured and $8.6 \%$ of plain). Almost one quarter of energy drinks (24.1\%) used references to sport.

\section{Better-for-you features and sugar content}

Most beverages with high or very high sugar content ( $n$ 759) carried a BFY feature on their label (85.8\%; Table 4). Of these beverages with high and very high amounts of sugar, $44.0 \%$ displayed a BFY feature related to energy or sugar content. Specifically, $34.3 \%$ of beverages with high and very high amounts of sugar displayed a no added sugar claim on the label and $6.7 \%$ indicated that the beverage was naturally sweetened or that the sugar was from fruit.

\section{Discussion}

The current study found BFY features present on $96.8 \%$ of sugar-containing beverage labels, with an average of 3.3 unique features per label. These features align products with being natural, emphasise their fruit and vegetable content, emphasise other nutrient contents, favourably position sugar content and suggest functional properties for the beverages. By using these BFY features, beverages may be given a 'health halo'(20).

\section{Sugar-containing beverages are positioned as natural}

Positioning beverages as natural appears to be at the centre of current BFY advertising, with over three-quarters of beverages in our study displaying natural features on their labels. Advertising products as natural is not new or unusual. Nature is often used to position products as intrinsically good, healthy, fresh and innocent ${ }^{(31)}$. The commodification of nature has previously been documented for bottled water ${ }^{(32)}$ and foods ${ }^{(31)}$. Our study shows that manufacturers are positioning sugar-containing beverages in the same way, with coconut waters, iced teas and juices heavily using natural connotations on labels. Using the key word 'natural' was the most direct way this association was achieved with a third of packages doing so.

The frequent presence of fruit and vegetables on sugarcontaining beverage labels also associates these beverages with being natural. The Coca-Cola Company has previously reported its efforts to 'capture the natural goodness of fruit and vegetables for beverage use ${ }^{\text {(33) }}$, highlighting the importance of this positioning for advertising beverages. In our study, fruit and vegetables were present on 
labels in a range of ways that appeal to varying levels of consumer consciousness. Fruit or vegetable flavours and images were highly prevalent across beverage types, implicitly associating the beverages with being natural. On the other hand, while listing the servings of fruit and vegetables in a beverage was less prevalent, this more explicitly associated beverages with being natural, and nutritious, equating the consumption of juice to that of whole foods.

Promoting the absence of artificial (non-natural) products on labels was another common way through which beverages were positioned as natural. Claims such as 'no artificial products, colours or flavours' can often be, and were, applied across beverage categories, including beverages such as sodas which could otherwise be considered inherently unhealthy.

\section{Sugar-containing beverages are positioned as a source of nutrition}

Altering the nutritional profile of foods and beverages through reformulation and fortification can be used by manufacturers to market products as a source through which nutrition is delivered ${ }^{(34)}$. Reformulation can be used to reduce the nutrients perceived by consumers as 'bad' for health and fortification increases the nutrients perceived as 'good' for health ${ }^{(34)}$. In our study, both of these strategies were used to promote sugar-containing beverages with labels addressing the sugar and vitamin/ mineral content of beverages.

Sugar is a nutrient of increasing concern to consumers ${ }^{(6,7)}$. Our study found that labels address concerns about sugar by favourably positioning the sugar content of beverages, most commonly though 'no added sugar' claims which were present on just under a third of labels. Beverages that included 'no added sugar' claims on their labels were still high in sugar, specifically free sugar. Notably problematic in this regard is $100 \%$ juices, with over threequarters of the $100 \%$ juices in our sample making a 'no added sugar' claim, while the mean sugar content of the category was surpassed only by soda and energy drinks.

Fortification of sugar-containing beverages can also be used to draw consumer attention towards positive nutrients rather than high sugar content. As such, the use of fortification positions these non-core (discretionary) products as a source of nutrients. This was evident on a quarter of labels which referred to the nutrient content of beverages, for example through claiming high vitamin and mineral content.

\section{Sugar-containing beverages are positioned as providing functional benefits}

Functionalism extends the concept of fortification from meeting adequate nutrient intake to providing optimal nutrition for enhanced health or bodily functions ${ }^{(34)}$. Functional beverages are often perceived to be novel and technological, invoking science through reference to 
physiological functions and health ${ }^{(35)}$. Although functional beverages comprise a relatively small segment of the market, their popularity is increasing ${ }^{(3)}$. Our study found that functionalism was advertised in two ways on beverage labels.

First, sports drink labels promoted functional benefits associated with achieving optimal sporting performance. Sports drink labels advertised electrolytes and the provision of optimal hydration for sporting performance. Scientific terms such as 'isotonic' and 'hypotonic' accompanied this positioning, further illustrating the scientific and functional positioning of these beverages.

Second, coconut waters were positioned as a 'natural' functional beverage, with the labels advertising electrolyte content and hydration. Unlike sports drinks, few coconut water labels made direct reference to sport and exercise. Linking functional benefits with the idea of being natural, coconut waters capitalised on the purported benefits of electrolyte consumption (namely, sporting performance) and appealed to consumers who desire natural products.

\section{Positioning high sugar beverages as better-for-you is misleading to consumers}

Prior research on consumer evaluation of beverages for health purposes is limited and has not explored how beverages are being positioned as healthy ${ }^{(37)}$. However, existing research on positioning foods as healthy or BFY suggests that many advertising features we identified on beverages align with how consumers evaluate a product as healthy. For example, Luomala et al. have shown how positioning a food as natural influences consumers' opinions on whether the food is healthy or not ${ }^{(38)}$. Irmak et al. found that renaming candy from 'candy chews' to 'fruit chews' can influence the health beliefs, and consumption, of candy ${ }^{(39)}$. Using BFY features on labels may therefore influence consumers' assessment of whether sugar-containing beverages are healthy, or healthier than other options.

Positioning beverages that contain high amounts of free sugar as BFY is potentially misleading. BFY features on labels disregard the source through which the purported benefits are being delivered ${ }^{(40)}$ and distract from the harms associated with consuming products high in free sugars $^{(27)}$. For example, advertising that juice contains 'no added sugar' or 'natural' sugar from fruit and vegetables distracts from the high free sugar content of these beverages. Through positioning sugar-containing beverages as BFY, consumers may be influenced to select products they believe are health-promoting, which are in fact potentially harmful when overconsumed.

\section{Public health implications}

Our study has highlighted the ways in which sugarcontaining beverages are being advertised as healthy on labels. The predominance of BFY features on these beverages further suggests that consumers are becoming increasingly concerned about health ${ }^{(7)}$, particularly in regard to sugar consumption from beverages ${ }^{(6)}$. Increased public concern around sugar consumption from beverages is a positive indicator for public health outcomes and it is not surprising that beverage manufacturers are implementing efforts to address this concern. Originally intended for improving public health, reformulation and fortification of foods and beverages has also been adopted by manufacturers and is a common technique used for advertising purposes ${ }^{(34)}$. However, the use of natural ingredients, increased vitamin and minerals and 'functional ingredients', as advertised on sugar-containing beverage labels in our study, does not offset the harms associated with high sugar consumption ${ }^{(27)}$ from these beverages. Reformulation that leads to positive public health outcomes in obesity and related noncommunicable diseases is likely to occur only through significant reduction in the sugar content of these beverages. Knowledge of the techniques used to position sugar-containing beverages as BFY can inform the development of public messaging that aims to increase community literacy and reduce population overconsumption of free sugars including sugar-containing beverages.

Our study has also highlighted that the positioning of sugar-containing beverages as BFY occurs despite existing regulations that aim to prevent the misleading advertising of unhealthy products as healthy ${ }^{(29)}$. We found that it was most common for implicit BFY features (such as fruit flavours and advertising natural ingredients) to be displayed on sugar-containing beverages. Research has demonstrated that implicit health-related labelling features, such as product titles ${ }^{(20)}$ and colour ${ }^{(21)}$, increase consumer perceptions of the healthfulness of discretionary foods. It has further been suggested that implicit features have a stronger effect on consumer health perceptions than explicit nutrition claims through creating a health halo effect $^{(20)}$. The prominence and effect of implicit healthand nutrition-related features, such as the BFY features identified in our study, therefore need to be considered in existing and future regulations, for example through broadening the scope of what is regulated. Such regulations can be further strengthened by restricting the use of all health- and nutrition-related features on labels to nondiscretionary foods and beverages. Australia has implemented such restrictions for health claims, with foods and beverages being required to meet a predefined nutrient profile score to be eligible to display health claims ${ }^{(11)}$. These restrictions have not been extended to nutrition claims, which may explain why a quarter of sugarcontaining beverages advertised the presence of specific nutrients on labels.

\section{Limitations}

We restricted our study to the labels of water-based sugarcontaining beverages, excluding milk-based beverages 
which may also be high in added sugar. Milk-based beverages may use different BFY features on their labels that were not identified in our study; analysis of the advertising features on sweetened milk labels would be complementary to our research. We also focused on advertising through labels, which may differ from advertising through other media. Further, while we have defined and measured BFY features on labels, our analysis cannot determine whether these features influence how people evaluate these beverages. The BFY features identified in the present study should be tested in experimental research to explore the effect of these features on consumers' perceptions and consumption of sugar-containing beverages.

\section{Conclusion}

Many sugar-containing beverage labels include features that imply these drinks are healthy, or healthier than alternative beverages. If BFY features lead consumers to believe these beverages are healthy, this may influence consumption, with consequent negative implications for the health of the public. Those working in obesity prevention and public health must find ways to counter and/or prevent the misleading advertising of sugar-containing beverages as healthy.

\section{Acknowledgements}

Financial support: Funding for this study was provided by an Australian Government Research Training Program Scholarship (A.L.B.) and an Ian Wilson Liberal Research Scholarship (A.L.B). The funders were not involved in the study design, analysis and interpretation of data, thus the authors were independent of the funder. It was the authors' decision to publish the findings of this study and the funders were not involved in the preparation of this manuscript. Conflict of interest: None. Authorship: A.L.B. developed the coding tool and collected and analysed the data, with scientific input from C.L.M. and A.J.B.-M. A.L.B. drafted the article. All authors contributed to the conceptualisation and design of the study and reviewed and revised the final version of the article. Ethics of human subject participation: This research project was exempt from review by a Human Research Ethics Committee as no human data were used and the research did not pose any foreseeable risk of harm or discomfort.

\section{Supplementary material}

To view supplementary material for this article, please visit https://doi.org/10.1017/S1368980018002392

\section{References}

1. Malik VS, Pan A, Willett WC et al. (2013) Sugar-sweetened beverages and weight gain in children and adults: a systematic review and meta-analysis. Am J Clin Nutr 98, 10841102.

2. Imamura F, O'Connor L, Ye Z et al. (2016) Consumption of sugar sweetened beverages, artificially sweetened beverages, and fruit juice and incidence of type 2 diabetes: systematic review, meta-analysis, and estimation of population attributable fraction. BrJ Sports Med 50, 496-504.

3. Malik VS, Popkin BM, Bray GA et al. (2010) Sugarsweetened beverages, obesity, type 2 diabetes mellitus, and cardiovascular disease risk. Circulation 121, 13561364.

4. Bernabe E, Vehkalahti MM, Sheiham A et al. (2014) Sugarsweetened beverages and dental caries in adults: a 4-year prospective study. J Dent $\mathbf{4 2}$, 952-958.

5. Popkin BM \& Hawkes C (2016) Sweetening of the global diet, particularly beverages: patterns, trends, and policy responses. Lancet Diabetes Endocrinol 4, 174-186.

6. Euromonitor International (2016) Better for you beverages in Australia. http://www.euromonitor.com/better-for-youbeverages-in-australia/report (accessed August 2016).

7. Amplify Snack Brands (2017) Better-for-you snacks: the new snacking reality. https://amplifysnackbrands.com/ documents/Amplify-2017-Snack-Study.PDF (accessed August 2017).

8. PepsiCo (2018) Explore PepsiCo brands: Better for you. http://www.pepsico.com/Brands/BrandExplorer\#betterfor-you (accessed July 2018).

9. Obesity Solutions Inititative (2011) Better-for-You Foods. It's Just Good Business. Washington, DC: Hudson Institute.

10. Campos S, Doxey J \& Hammond D (2011) Nutrition labels on pre-packaged foods: a systematic review. Public Health Nutr 14, 1496-1506.

11. Food Standards Australia New Zealand (2016) Australia New Zealand Food Standards Code - Standard 1.2.7 Nutrition, Health and Related Claims. Canberra, ACT: Federal Register of Legislation, Australian Government.

12. Abrams KM, Evans C \& Duff BR (2015) Ignorance is bliss. How parents of preschool children make sense of front-ofpackage visuals and claims on food. Appetite 87, 20-29.

13. Dean M, Lahteenmaki L \& Shepherd R (2011) Nutrition communication: consumer perceptions and predicting intentions. Proc Nutr Soc 70, 19-25.

14. Williams P (2005) Consumer understanding and use of health claims for foods. Nutr Rev $\mathbf{6 3}, 256-264$.

15. Gorton D, Mhurchu CN, Bramley D et al. (2010) Interpretation of two nutrition content claims: a New Zealand survey. Aust N Z J Public Health 34, 57-62.

16. Kaur A, Scarborough P \& Rayner M (2017) A systematic review, and meta-analyses, of the impact of health-related claims on dietary choices. Int J Behav Nutr Phys Act 14, 93.

17. Elliott C (2016) How Canadians Communicate VI: Food Promotion, Consumption, and Controversy. Edmonton, AB: Athabasca University Press.

18. Franco-Arellano B, Bernstein JT, Norsen S et al. (2017) Assessing nutrition and other claims on food labels: a repeated cross-sectional analysis of the Canadian food supply. BMC Nutr 3, 74 .

19. Christoforou A, Dachner N, Mendelson R et al. (2018) Frontof-package nutrition references are positively associated with food processing. Public Health Nutr 21, 58-67.

20. Fernan C, Schuldt JP \& Niederdeppe J (2018) Health halo effects from product titles and nutrient content claims in the context of 'protein' bars. Health Commun 33, 1425-1433.

21. Schuldt JP (2013) Does green mean healthy? Nutrition label color affects perceptions of healthfulness. Health Commun 28, 814-821. 
22. Roy Morgan Research (2016) Supermarket sweep: ALDI's share of the Aussie market still rising. http://www.roymorgan. com/findings/6762-supermarket-sweep-aldis-share-of-aussiemarket-still-rising-201604142258 (accessed July 2016).

23. Australian Bureau of Statistics (2013) Census of Population and Housing: Socio-Economic Indexes for Areas (SEIFA), Australia, 2011. http://www.abs.gov.au/ausstats/abs@.nsf/ Lookup/by\%20Subject/2033.0.55.001 2011 Main\%20Fea tures Main\%20Page 1 (accessed July 2016).

24. Williams P, Yeatman H, Ridges L et al. (2006) Nutrition function, health and related claims on packaged Australian food products - prevalence and compliance with regulations. Asia Pac J Clin Nutr 15, 10-20.

25. Dachner N, Mendelson R, Sacco J et al. (2015) An examination of the nutrient content and on-package marketing of novel beverages. Appl Physiol Nutr Metab 40, 191-198.

26. Rayner M, Wood A, Lawrence M et al. (2013) Monitoring the health-related labelling of foods and non-alcoholic beverages in retail settings. Obes Rev 14, Suppl. 1, 70-81.

27. World Health Organization (2015) Guideline: Sugar Intake for Adults and Children. Geneva: WHO.

28. Kondracki NL, Wellman NS \& Amundson DR (2002) Content analysis: review of methods and their applications in nutrition education. I Nutr Educ Behav 34, 224-230.

29. Food Standards Australia New Zealand (2016) Australia New Zealand Food Standards Code - Schedule 4 - Nutrition, Health and Related Claims. Canberra, ACT: Federal Register of Legislation, Australian Government.
30. Feng GC (2013) Underlying determinants driving agreement among coders. Qual Quant 47, 2983-2997.

31. Hansen A (2002) Discourses of nature in advertising. Communications 27, 499-511.

32. Opel A (1999) Constructing purity: bottled water and the commodification of nature. J Am Cult 22, 67-76.

33. Short D (2005) When science met the consumer: the role of industry. Am J Clin Nutr 82, 1 Suppl., 256S-258S.

34. Scrinis G (2016) Reformulation, fortification and functionalization: Big Food corporations' nutritional engineering and marketing strategies. J Peasant Stud 43, 17-37.

35. Eden S (2009) Food labels as boundary objects. Public Underst Sci 20, 179-194.

36. Siro I, Kapolna E, Kapolna B et al. (2008) Functional food. Product development, marketing and consumer acceptance a review. Appetite 51, 456-467.

37. Kim H \& House LA (2014) Linking consumer health perceptions to consumption of nonalcoholic beverages. Agric Resour Econ Rev 43, 1-16.

38. Luomala H, Jokitalo M, Karhu H et al. (2015) Perceived health and taste ambivalence in food consumption. J Consum Mark 32, 290-301.

39. Irmak C, Vallen B \& Robinson SR (2011) The impact of product name on dieters' and nondieters' food evaluations and consumption. J Consum Res 38, 390-405.

40. Scrinis G (2013) Nutritionism. The Science and Politics of Dietary Advice. New York: Columbia University Press. 